\title{
An Exploration of Some Effects of Social Innovation Capability in Social Enterprises in Mexico
}

\author{
Judith Cavazos-Arroyo ${ }^{1}$
}

\begin{abstract}
Social enterprises need to develop processes that create social value based on their initiative to find solutions to social problems through innovative strategies. The objective of this research was to examine the effect of social innovation capability, social marketing achievements and enterprise social performance as antecedents of social value creation in social enterprises in Mexico. An explanatory and cross-sectional study was developed for 106 managers of social enterprises in Mexico. Structural Equation Modelling was applied using Partial Least Squares to test five hypotheses. The results supported that social innovation capability has a positive and direct effect on social value creation, social marketing achievements and enterprise social performance. Similarly, these last two showed a direct effect on social value creation. Particularly, it was identified that social innovation capability had the greatest effect on social value creation. The implications of the results are discussed.
\end{abstract}

Keywords: Social innovation; Social marketing achievements; Enterprise social performance; Social value creation

Submitted: June $6^{\text {th }}, 2020 /$ Approved: December $16^{\text {th }}, 2020$

\section{Introduction}

Social enterprises need to make an effort to create a sustainable business model, reach the fullness of their social mission and obtain the greatest possible social impact through a new way of doing business (Pineda, 2018). They develop processes that create social value based on their initiative to find solutions to social problems through innovative strategies that involve the combination of resources and the exploitation of opportunities to stimulate social change (Dees, 1998). However, in practice, most of these types of businesses need to resolve tensions and conflicts related to their duality since social value is often sacrificed while attempting to capture economic value. Still, social value creation is perceived as an ambiguous aspect that is complex to measure and to understand its interactions with other variables (Hlady-Rispal \& Servantie, 2018).

Regarding social value generation, social enterprises face several challenges, for instance, social improvements are not always appreciated by the market, growth will not necessarily improve social conditions, making it difficult to determine if the company creates sufficient social value to justify the resources used (Dees, 1998). Even in recent years, there is continuous debate among social enterprise experts about the creation of internal and external social value (Bull et al., 2018); consequently, it is necessary to continue investigating aspects that affect social value and its nature. However, the participants of the research are those who, from their organizational contexts, generate or not social innovation and may or may not affect the results of social change (Newth, 2018). Additionally, social marketing achievements and enterprise performance can be key aspects of contributing to increasing the social value of an organization.

Among the aspects that can contribute to the creation of new social value are the enterprise's social performance and its social marketing achievements. However, several scholars have recommended continuing to work on the theoretical bases and empirical validity of the company's social performance (Azevedo, dos Santos \& Boaventura, 2016). Similarly, social marketing needs to be assertive while serving the mission of the social enterprise, participate in the continuous and effective process of social innovation to deliver results in social change with limited resources (Holweg \& Lienbacher, 2011). Therefore, the objective of this research is focused on examining the effect of social innovation capability, social marketing achievements and enterprise social performance as antecedents of social value creation in social enterprises in Mexico.

\section{Literature review and hypotheses}

Social value is created when resources, inputs, processes or policies combine to generate improvements in in people's lives or in society in general (Emerson, Wachowicz, \& Chun, 2001). Social value creation can be accomplished through innovative strategies that involve combining resources and exploiting opportunities to stimulate social change, the satisfaction of social needs and the development of social goods and services (Morris, Webb, \& Flanklin, 2011). Social enterprises prioritize social value over economic value (Dees, 1998). The company combines resources to develop a value proposition, which communicates the benefits that will create value for different stakeholders (Verstraete \& Jouison-Laffitte, 2011). Social value is subjective, changing and dynamic and it cannot be evaluated from the traditional principles of supply and demand. Many of these efforts show results up to several years in the future, nevertheless their investment is useful to create bonds between people who have specific basic needs and organizations that offer solutions and generate new conversations, negotiations and markets (Spohrer, Demirkan, \& Lyons, 2015).

(1) Universidad Popular Autónoma del Estado de Puebla

E-mail: cavazosjudith03@gmail.com

ISSN: 0718-2724. (http://jotmi.org)

Journal of Technology Management \& Innovation (c) Universidad Alberto Hurtado, Facultad de Economía y Negocios. 
Social innovation could be conceptualized as "a novel solution to a social problem that is more effective, efficient and sustainable...than existing solutions and for which the value created accrues primarily to society as a whole rather than private individuals" (Phills, Deiglmeier, \& Miller, 2008, p.36). Social businesses seek to produce social innovations in order to offer new products or services. Social innovation implies a process and an outcome (Bitzer \& Hamann, 2015). This involve many external and organizational factors, including knowledge, learning, searching and exploring in a particular context that requires the combination of ideas and resources to help an organization achieve its results (Lundvall, 2010). Social innovation as a process of generating ideas, as well as its selection and implementation to solve the challenges of a sociotechnical system, requires collective participation (Bitzer \& Hamann, 2015). Even when these innovations are not transferred to different contexts, accumulated learning can be very valuable while developing of innovation capability over time (Seelos \& Mair, 2012).

Social marketing is a planned method for social innovation because applying marketing principles in the social context. It refers to a process that applies marketing principles and techniques to create, communicate, and deliver value in order to influence behaviors of the target audience aiming to benefit society (Kotler \& Lee, 2008). Achieving voluntary change to adopt new attitudes, beliefs, values or behaviors in primary audiences requires a social innovation platform connected to the marketing strategy with the purpose of persuading individuals to adopt new behaviors (Bonča, Udovč, \& Rodela, 2017). It is possible to assume that social innovation in its different manifestations, including innovations in social marketing itself, can contribute to obtaining better results in the achievements of social marketing. Therefore, the following hypothesis is proposed:

H1. Social innovation capability positively affects social marketing achievements.

Social innovation capability positively affects social marketing achievements (Frederick, 1994). Social achievement has become a relevant aspect for all types of businesses and it refers to the configuration of principles of social responsibility, social responsiveness, policies, programs, and outcomes related to the firm's societal relationships (Wood, 1991). Previous research in commercial firms has found a relationship between innovation and firm performance in small and medium sized enterprises (Roach, Ryman, \& Makani, 2016). Choi, Kim and Yang (2018) found that medium-sized commercial SMEs present stronger social performance than small companies do. Similarly, in the context of social business, it has been found that social innovations constitute a business opportunity that not only increases welfare, as well as the firm's performance and its competitive advantage (Furmańska-Maruszak \& Sudolska, 2016). Thus, it is possible suppose that:

H2. Social innovation capability positively affects the enterprise's social performance, controlled by organizational size.

As mentioned above, the objectives of social marketing are achieved through the behavior change of the target audience using the principles of social change. If the social marketing works, it can contribute to create greater social value (Short, Moss, \& Lumpking, 2009). This requires for the social marketing program (developed by the social enterprise) to actively create value emerging from the interactions with their stakeholders (Vargo \& Lush, 2004). The processes of social entrepreneurship are inserted in a specific socio-economic context that must be understood for the creation of social value (Chell, 2007). Particularly social businesses should pay special attention to operational processes, including marketing, as they are fundamental to preserve entrepreneurial activity at individual and group level (Chell, 2007). Thus, the following hypothesis is proposed:

H3: Social marketing achievements affect social value creation.

Commonly, social performance is evaluated according to the context in which it is applied. Most of these approaches are supported by Corporate Social Responsibility or Stakeholders theories, where the environmental community and employee aspects are usually included (Azevedo et al., 2016). The company's social performance can be developed by integrating commercial aspects and social considerations, in order to create new value in the market and community (Ciravegna \& da Fonseca, 2016).

Each social venture needs to produce the mechanisms and strategies to pursue social value (Mendoza-Abarca \& Mellema, 2016). The performance of a social enterprise capitalizes the efforts of diverse stakeholders within the value chain through the social value created for beneficiary groups (including producers, workers, owners, communities and society) while improving the well-being of the people directly or indirectly involved (Srivetbodee, Igel, \& Kraisornsuthasinee, 2017). Therefore, the following hypothesis is proposed:

\section{H4. Enterprise social performance affects social value creation}

Although social innovations could be presented as products, services, processes, markets, platforms, organizational forms, or business models (Choi \& Majumdar, 2015), the social innovation capability has an essentially immaterial structure. This structure brings with it a social change established as new social practices that will eventually be institutionalized (Cajaiba-Santana, 2014). This capability is understood, as a fundamental capital supported by the interaction of the collective capacity to innovate around the production of new knowledge and its explicit aim is the creation of social value and social change (Choi \& Majumdar, 2015). If it is accepted by social participants after dissemination in social groups through market mechanisms, it will generate new skills, practices and routines (Kopp, 2011).

Social innovation capability works to produce value with less focus on financial profit and more on social needs, collaborations and social relationships, contributing to the redistribution systems and improving human well-being (Von Jacobi, Edmiston, \& Ziegler, 2017). Social value creation requires innovation, pro-activeness and risk management behavior associated to the social mission (Urban, 2010). Consequently, social innovation promotes the creation of value that is accumulated primarily for society rather than private individuals (Phills et al., 2008). Thus, the following hypothesis is proposed:

H5. Social innovation capability affects Social value creation 


\section{Method}

Explanatory and cross-sectional research was developed to 324 social enterprises in Mexico. The survey was answered by telephone or electronically and 106 responses were obtained. The response rate was of $32.7 \%$ from Mexican social enterprises list (Red Interdisciplinaria de la Innovación para la Transformación Social [RIITS], 2017). This study used existing measures from past research, all of them measured with seven-point Likert scales from $1=$ totally disagree to $7=$ totally agree. The social innovation scale was adapted from Keskin (2006), the social value creation and the social marketing achievements were measured with scales from Liu, Eng and Takeda (2015) and the social performance scale from Lortie, Castro Geovanni and Cox (2017). The control variable included in the analysis was the size of the social enterprise measured with a five point scale ( $1=$ very small, $5=$ very large) because the unwillingness respondents to mention directly their financial information. The data analysis was carried out in two stages according to what was suggested by Kline (2015) for the procedure of analysis of structural models and the proposed structural model was evaluated using a method based on Partial Least Squares with the software Smart PLS, V3.

\section{Results}

Enterprises' demographic characteristics. The most relevant enterprises' characteristics show that $74.5 \%$ produce and trade products or services and $25.5 \%$ only are focused on trading products. $56.6 \%$ do not have volunteers, $37.7 \%$ do not sell on the internet, $35.8 \%$ are classified as very small, $35.8 \%$ as small, $24.5 \%$ has medium size, $1.9 \%$ large and $1.9 \%$ very large.

Measurement model. When starting the measurement model, it included 20 items. All the statements of the scales included in the investigation were of a reflective nature and, according to what is suggested in the literature, those who had minimum loads of 0.70 were retained (Hair et al., 2016). In this investigation, the items eliminated were (Appendix): one of Social Innovation (SI1) and two from Social Value Creation (SVC1, SVC2). The rest of the loads associated with each of the scales were greater than the established criteria (Table 1). In addition, the Cronbach alpha ( $\alpha$ ) and the Composite Reliability (CR) of each of the reflective constructs exceeded the required minimum of 0.70 (Hair et al., 2016). The latent variables showed internal consistency (Table 1) and the model showed convergent validity through the Average Variance Extracted (AVE) of all the constructs, exceeding the value of 0.50 as minimum required (Fornell \& Larcker, 1981).

Table 1. Loads associated to the items, reliability and convergent validity

\begin{tabular}{|c|c|c|c|c|c|}
\hline \multirow{4}{*}{ Social innovation } & SI2 & 0.909 & \multirow{4}{*}{0.873} & \multirow{4}{*}{0.912} & \multirow{4}{*}{0.722} \\
\hline & SI4 & 0.828 & & & \\
\hline & SI5 & 0.804 & & & \\
\hline & SMA1 & 0.800 & & & \\
\hline \multirow{3}{*}{ Social marketing achievements } & SMA3 & 0.848 & \multirow{3}{*}{0.93} & \multirow{3}{*}{0.946} & \multirow{3}{*}{0.778} \\
\hline & SMA4 & 0.896 & & & \\
\hline & SMA5 & 0.954 & & & \\
\hline \multirow{2}{*}{ Enterprise Social Performance } & DS1 & 0.78 & \multirow{3}{*}{0.786} & \multirow{2}{*}{0.861} & \multirow{2}{*}{0.608} \\
\hline & DS4 & 0.753 & & & \\
\hline \multirow{3}{*}{ Social Value Creation } & VS3 & 0.824 & & \multirow{3}{*}{0.89} & \multirow{3}{*}{0.729} \\
\hline & VS4 & 0.895 & \multirow[t]{2}{*}{0.815} & & \\
\hline & VS5 & 0.842 & & & \\
\hline
\end{tabular}

Similarly, the discriminant validity of the constructs was verified through three methods: cross loadings, Fornell-Larcker criterion and Heterotrait-Monotrait Ratio [HTMT]. Table 2 shows the indicators of the three criteria. Regarding the cross loadings, the greater weight of each variable loads in its respective construct, with weights greater than 0.70. Concerning the Fornell-Larcker criterion, each latent variable explains the variance of its own indicator instead of the variance of other latent variables and finally, Hererotrait-Monotrait Ratio (HTMT) moved away from 1 (Kline, 2015). 
Table 2. Discriminant validity criterions

\begin{tabular}{|c|c|c|c|c|}
\hline \multicolumn{5}{|c|}{ Cross loadings } \\
\hline & Social innovation & Social marketing achievements & $\begin{array}{c}\text { Enterprise social } \\
\text { performance }\end{array}$ & $\begin{array}{l}\text { Social value } \\
\text { creation }\end{array}$ \\
\hline SP1 & 0.289 & 0.116 & 0.780 & 0.379 \\
\hline SP3 & 0.286 & 0.270 & 0.800 & 0.436 \\
\hline SP4 & 0.246 & 0.243 & 0.753 & 0.358 \\
\hline SI4 & 0.828 & 0.145 & 0.274 & 0.428 \\
\hline SI5 & 0.804 & 0.157 & 0.307 & 0.651 \\
\hline SMA1 & 0.046 & 0.800 & 0.225 & 0.175 \\
\hline SMA2 & 0.157 & 0.907 & 0.143 & 0.247 \\
\hline SMA3 & 0.108 & 0.848 & 0.252 & 0.221 \\
\hline SVC5 & 0.592 & 0.243 & 0.356 & 0.842 \\
\hline \multicolumn{5}{|l|}{ Heterotrait-Monotrait Ratio (HTMT) } \\
\hline & Social innovation & Social marketing achievements & Enterprise social performance & Social value creation \\
\hline \multicolumn{5}{|l|}{ Social innovation } \\
\hline Social marketing achievements & 0.160 & & & \\
\hline Enterprise social performance & 0.414 & 0.273 & & \\
\hline Social value creation & 0.673 & 0.328 & 0.642 & \\
\hline \multicolumn{5}{|l|}{ Forner-Larcker criteron } \\
\hline & Social innovation & Social marketing achievements & Enterprise social performance & Social value creation \\
\hline Social innovation & 0.850 & & & \\
\hline
\end{tabular}

Structural Model Evaluation. The results confirm the effects between the constructs showed in the proposed model, indicating that the five hypotheses tested had an adequate explanatory power (Table 3). The magnitude of $R^{2}$ and $R^{2}$ adjusted show the suitability of the model to predict the indicators of latent constructs (Table 4). The analysis showed that there was not enough evidence to prove that the control variable -organizational size- had effect on the enterprise social performance $(\beta=0.075, \mathrm{p}>0.05)$. Table 3 shows the $t$ statistics for the relations proposed and Figure 1 presents the structural model.

Table 3. Results of the analysis of the structural equation model

\begin{tabular}{l|l|c|c|c}
\hline Proposed hypotheses & Hypothesis & Coefficient Path $(\boldsymbol{\beta})$ & t statistics & Hypothesis decision \\
\hline Social innovation capability $\rightarrow$ Social marketing achievements & H1 & 0.159 & 2.031 & Supported \\
\hline Social innovation capability $\rightarrow$ Enterprise social performance & H2 & 0.337 & 3.140 & Supported \\
\hline Social marketing achievements $\rightarrow \quad$ Social value creation & H3 & 0.144 & 2.564 & Supported \\
\hline Enterprise social performance $\rightarrow \quad$ Social value creation & H4 & 0.317 & 3.671 & Supported \\
\hline Social innovation capability $\rightarrow$ Social value creation & H5 & 0.467 & 6.170 & Supported \\
\hline
\end{tabular}

Note: $\mathrm{n}=106$. Bootstrapping 500 samples; $\beta=$ Standardized coefficient 
Figure 1. Structural equation model

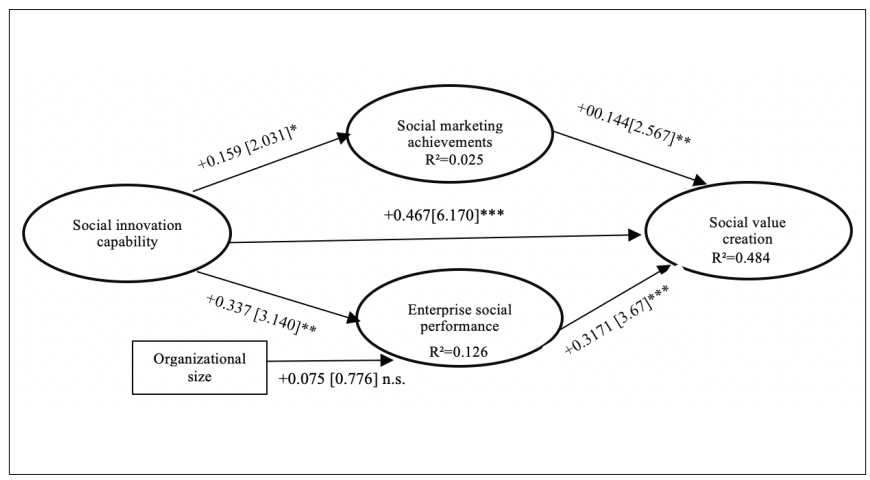

Note. ${ }^{*} a<0.05 ;{ }^{* *} a<0.01 ;{ }^{* *} a<0.001 ;$ n.s. $=$ not significant

Table 4. $\mathrm{R}^{2}$ effects

\begin{tabular}{l|c|c|c}
\hline Constructs effect & $\begin{array}{c}\text { Path coe- } \\
\text { fficient }\end{array}$ & Correlation & $\begin{array}{c}\text { \% explained } \\
\text { variance }\end{array}$ \\
\hline Social mkt-Social value & 0.144 & 0.291 & 0.042 \\
\hline $\begin{array}{l}\text { Social performance-Social } \\
\text { value }\end{array}$ & 0.317 & 0.512 & 0.162 \\
\hline $\begin{array}{l}\text { Social innovation-Social } \\
\text { value }\end{array}$ & 0.467 & 0.600 & 0.280 \\
\hline & & $\mathrm{R}^{2}=$ & 0.484 \\
\hline
\end{tabular}

Indirect and total effects. The proposed model shows that in addition to the direct effects, an indirect effect may exist between Social innovation capability and Social value creation. The results confirmed the indirect effect (Effect=0.130, $\mathrm{t}=3.519, \mathrm{p}=0.000)$. Similarly, the total effect to social value creation was calculated by the sum of the significant direct and indirect effects and the result was of 0.596 considered as notable (Hair et al., 2016).

\section{Discussion}

The purpose of this investigation was to examine the effect of social innovation capability, social marketing achievements and enterprise social performance as antecedents of social value creation in social enterprises in Mexico. The first hypothesis stated that social innovation capability would have a positive influence on the social marketing achievements and was supported. Social innovation may help social enterprises to improve their performance (Lundvall, 2010) and it is required to develop an effective marketing strategy in order to adopt new behaviors (Bonča et al., 2017).

Similarly, we found a positive effect of social innovation capability impacting enterprise social performance, although the effect of the social organization's size was not significant as found in research in commercial companies (Roach et al., 2016). A possible explanation could be that in Mexico, social enterprises require more support to develop and expand their social impact beyond its local context (Pineda, 2018). Despite this, social innovation capability affects the enterprise's social performance supporting what was found in previous research (Furmańska-Maruszak \& Sudolska, 2016).
In addition, the direct and indirect effects of social innovation capability on social value creation were confirmed. The direct effect of social innovation on social value creation is the strongest effect in the model, supporting the fifth hypothesis. In addition to novelty, it requires resources, collective capacity and time to develop the social innovation capability (Seelos \& Mair, 2012). Also, the results confirmed that social marketing achievement and social performance are antecedents of social value creation, supporting hypotheses three and four. These results were consistent with the postulates in the literature, since marketing is a driver to create social value (Short, Moss, \& Lumpking, 2009). Also, the integration of social value into business processes and its effect on social performance contributes significantly to capitalize the efforts of the interactions between diverse agents (Vargo \& Lush, 2004).

This investigation presented some limitations; a cross-sectional study was developed for the Mexican social enterprises and only $32.7 \%$ accepted to participate. Future research could consider a longitudinal design to compare the effects of the variables in social value creation considering situational and temporal factors. In addition, it is recommended studying how these companies may maintain sustainable social value in the long-term. Furthermore, since not all the capabilities have equal importance, future research can study how other capabilities affect social value creation.

\section{Managerial implications}

This research showed some antecedents to facilitate the understanding of social value creation in social enterprises in an emergent country. Most of these enterprises offer solutions for the most urgent and immediate needs of human beings in their value chain. Developing social innovation capability becomes a strategic issue due to the holistic significance and weigh related to all the other variables studied. Transforming scarce and limited resources into innovation capability requires developing efficient resource deployment and collaborating with the ecosystem of the social business environment in order to create social value and a competitive advantage.

\section{References}

Azevedo, A. C., dos Santos, D. P., \& Boaventura, J. M. G. (2016). Corporate Social Performance: análise da evolução do construto nos estudos empíricos publicados entre 1975 e 2014. Perspectivas Contemporâneas, 11(3), 19-38.

Bitzer, V., \& Hamann, R. (2015). The business of social and environmental innovation (pp. 3-24). In V. Bitzer, R. Hamann, R. Hall, M. Griffin-El (Eds.). The Business of Social and Environmental Innovation. New frontiers in Africa. USA: Springer International Publishing.

Bonča, S., Udovč, A., \& Rodela, R. (2017). A social marketing perspective on road freight transportation of fresh fruits and vegetables: a Slovene case. Economic research-Ekonomska istraživanja, 30(1), 11321151. https://doi.org/10.1080/1331677X.2017.1314820 
Bull, M., Ridley-Duff, R., Whittam, G., \& Baines, S. (2018). Challenging tensions and contradictions: Critical, theoretical and empirical perspectives on social enterprise. International Journal of Entrepreneurial Behavior \& Research, 24(3), 582-586. https://doi.org/10.1108/ IJEBR-05-2018-526

Cajaiba-Santana, G. (2014). Social innovation: Moving the field forward. A conceptual framework. Technological Forecasting and Social Change, 82, 42-51. https://doi.org/10.1016/j.techfore.2013.05.008

Chell, E. (2007). Social enterprise and entrepreneurship: Towards a convergent theory of the entrepreneurial process. International small business journal, 25(1), 5-26. https://doi. org/10.1177/0266242607071779

Choi, N., \& Majumdar, S. (2015). Social innovation: towards a conceptualisation. In Satyajit Majumdar, S., Guha, S., \& Marakkath, N. Technology and innovation for social change (pp. 7-34). New Delhi: Springer.

Ciravegna, L.M., \& da Fonseca, M. (2016). Sustainability and pope francis's encyclical 'laudato si' (2015) the role of social enterprises. European Journal of Science and Theology, 12(2), 53-64.

Dees, J.G. (1998). The meaning of "social entrepreneurship." Comments and suggestions contributed from the Social Entrepreneurship Founders Working Group. Durham, NC: Center for the Advancement of Social Entrepreneurship, Fuqua School of Business, Duke University. Retrieved from rom http://faculty.fuqua.duke.edu/ centers/case/files/ dees-SE.pdf

Emerson, J., Wachowicz, J., \& Chun, S. (2001). Social Return on Investment (SROI): Exploring aspects of value creation. HBS Working Knowledge, 1, 1-3.

Fornell, C., \& Larcker, D. F. (1981). Evaluating Structural Equation Models with Unobservable Variables and Measurement Error: Algebra and Statistics. Journal of Marketing Research, 18(3), 382-388. https://doi.org/10.1177/002224378101800104

Frederick, W. C. (1994). From CSR1 to CSR2: The maturing of business-and-society thought. Business \& Society, 33(2), 150-164. https:// doi.org/10.1177/000765039403300202

Furmańska-Maruszak, A., \& Sudolska, A. (2016). Social innovations in companies and in social economy enterprises. Comparative Economic Research, 19(3), 169-191. https://doi.org/10.1515/cer-2016-0026

Hair, J. F., Hult, T.G., Ringle, C., \& Sarstedt, M. (2016). A primer on partial least squares structural equation modeling (PLS-SEM). UK: Sage Publications.

Hlady-Rispal, M., \& Servantie, V. (2018). Deconstructing the way in which value is created in the context of social entrepreneurship. International Journal of Management Reviews, 20(1), 62-80. https://doi. org/10.1111/ijmr.12113
Holweg, C., \& Lienbacher, E. (2011). Social marketing innovation: New thinking in retailing. Journal of Nonprofit \& Public Sector Marketing, 23(4), 307-326. https://doi.org/10.1080/10495142.2011.623548

Keskin, H. (2006). Market orientation, learning orientation, and innovation capabilities in SMEs: An extended model. European Journal of innovation management, 9(4), 396-417. https://doi. org/10.1108/14601060610707849

Kline, R. B. (2015). Principles and practice of structural equation modeling. N.Y.: Guilford publications.

Kopp, R. (2011). Social Innovation and Interactive Value Creation as Strategic Demand for Management. In Hülsmann, M., Pfeffermann, N. (Eds.). Strategies and communications for innovations: An integrative management view for companies and networks. London: Springer Science \& Business Media.

Kotler, P. A., \& Lee, N. L. (2008). Social marketing: Influencing behaviors for good (3rd ed.). Thousand Oaks: Sage.

Liu, G., Eng, T. Y., \& Takeda, S. (2015). An investigation of marketing capabilities and social enterprise performance in the UK and Japan. Entrepreneurship Theory and Practice, 39(2), 267-298. https://doi. org/10.1111/etap.12041

Lortie, J., Castrogiovanni, G. J., \& Cox, K. C. (2017). Gender, social salience, and social performance: how women pursue and perform in social ventures. Entrepreneurship \& Regional Development, 29(1-2), 155-173. https://doi.org/10.1080/08985626.2016.1255433

Lundvall, B.A. (2010). Introduction. (pp. 1-20). En B.A. Lundvall (Ed.). National systems of innovation. Towards a theory of innovation and interactive learning (Vol. 2). London/New York: Anthem Press.

Morris, M. H., Webb, J. W., \& Franklin, R. J. (2011). Understanding the manifestation of entrepreneurial orientation in the nonprofit context. Entrepreneurship Theory and Practice, 35(5), 947-971. https:// doi.org/10.1111/j.1540-6520.2011.00453.x

Newth, J. (2018). “Hands-on” vs “arm's length” entrepreneurship research: Using ethnography to contextualize social innovation. International Journal of Entrepreneurial Behavior \& Research, 24(3), $683-$ 696. https://doi.org/10.1108/IJEBR-09-2016-0315

Phills, J. A., Deiglmeier, K., \& Miller, D. T. (2008). Rediscovering social innovation. Stanford Social Innovation Review, 6(4), 34-43.

Pineda, A. (2018/08/28). Las empresas sociales requieren un regimen especial. Expansión. Retrieved from https://expansion.mx/emprendedores/2018/08/28/las-empresas-sociales-quieren-un-regimenespecial

Red Interdisciplinaria de la Innovación para la Transformación Social [RIITS] (2017). Social enterprises in Mexico list. Mexico: Author. 
Roach, D. C., Ryman, J. A., \& Makani, J. (2016). Effectuation, innovation and performance in SMEs: an empirical study. European Journal of Innovation Management, 19(2), 214-238.

Seelos, C., \& Mair, J. (2012). Innovation is not the Holy Grail. Stanford Social Innovation Review, Fall, 44-49.

Short, J. C., Moss, T. W., \& Lumpkin, G. T. (2009). Research in social entrepreneurship: Past contributions and future opportunities. Strategic Entrepreneurship Journal, 3, 161-194. https://doi.org/10.1002/sej.69

Spohrer, J., Demirkan, H., \& Lyons, K. (2015). Social Value: A Service Science Perspective. En K. Kijima (Ed.), Service Systems Science. Tokyo: Springer.

Srivetbodee, S., Igel, B., \& Kraisornsuthasinee, S. (2017). Creating Social Value Through Social Enterprise Marketing: Case Studies from Thailand's Food-Focused Social Entrepreneurs. Journal of Social Entrepreneurship, 8(2), 201-224. https://doi.org/10.1080/19420676.2017 .1371630
Urban; B. (2010). Creating value and innovation through social entrepreneurship (pp. 115-138). In Urban, B. Frontiers in entrepreneurship. London: Springer.

Vargo, S.L. \& Lusch, R.F. (2004). Evolving to a new dominant logic for marketing, Journal of Marketing, 68 ( January ), 1-17.

Verstraete, T. \& Jouison-Laffitte, E. (2011). A conventionalist theory of the business model in the context of business creation for understanding organizational impetus. Management International, 15, 109124. https://doi.org/10.7202/1003453ar

Von Jacobi, N., Edmiston, D., \& Ziegler, R. (2017). Tackling marginalisation through social innovation? Examining the EU social innovation policy agenda from a capabilities perspective. Journal of Human Development and Capabilities, 18(2), 148-162. https://doi.org/10.1080 /19452829.2016.1256277

Wood, D. J. (1991). Corporate social performance revisited. Academy of Management Review, 16(4), 691-718. https://doi.org/10.5465/ amr.1991.4279616 


\section{Appendix}

\section{Social Innovation}

SI1.Our company is often the first to market with new social/ecological products and services

SI2.Our company frequently tries out new ideas

SI3. Our company seeks out new ways to do things

SI4.Our company is creative in its methods of operation

SI5.Our new social/ecological product/service introduction has increased over last three or four years

\section{Social marketing achievement}

SMA1. Acquiring new donors

SMA2. Acquiring new volunteers

SMA3.Increasing donation amount from current donor

SMA4.Increasing volunteer hours from current volunteer

SMA5.Growth in overall donation/volunteer time

\section{Social value creation}

SVC1. This company has bidding for public service contract

SVC2. This company has bidding government (or its funding body's) grants for enterprise activities

SVC3. This company serves more beneficiaries in the community

SVC4. This company provides more social products and/or services

SVC5. This company has expanded social products and/or services to different locations

Enterprise Social performance

How satisfied are you with your organization's:

SP1. Fulfillment of beneficiary needs

SP2. Services delivered to beneficiaries

SP3.Programs delivered to beneficiaries

SP4. Resources delivered to beneficiaries 